\title{
Immune cell membrane fatty acids and inflammatory marker, C-reactive protein, in patients with multiple sclerosis
}

\author{
Gloudina Hon ${ }^{1}$, Mogamat Hassan ${ }^{1}$, Susan Janse van Rensburg ${ }^{2}$, Stefan Abel $^{3}$, De Wet Marais ${ }^{4}$, \\ Paul van Jaarsveld ${ }^{4}$, Cornelius Smuts ${ }^{4,5}$, Franclo Henning ${ }^{6}$, Rajiv Erasmus ${ }^{7}$ and Tandi Matsha ${ }^{1 *}$ \\ ${ }^{1}$ Department of Biomedical Technology, Faculty of Health and Wellness Science, Cape Peninsula University of Technology, \\ PO Box 1906, Bellville, 7530 Cape Town, South Africa \\ ${ }^{2}$ National Health Laboratory Services, Tygerberg, Cape Town, South Africa \\ ${ }^{3}$ PROMEC Unit and Nutritional Intervention Research Unit (NIRU), Cape Town, South Africa \\ ${ }^{4}$ South African Medical Research Council, Cape Town, South Africa \\ ${ }^{5}$ North-West University (Potchefstroom Campus), Potchefstroom, South Africa \\ ${ }^{6}$ Division of Neurology, Tygerberg Academic Hospital, Cape Town, Western Cape, South Africa \\ ${ }^{7}$ Division of Chemical Pathology, Faculty of Health Sciences, University of Stellenbosch, Tygerberg Campus, South Africa \\ (Received 8 October 2008 - Revised 20 January 2009 - Accepted 22 April 2009 - First published online 19 May 2009)
}

\begin{abstract}
Measurement of fatty acids in biological fluids and cell membranes including leucocytes from multiple sclerosis patients is inconsistent. The objective of the present study was to investigate the fatty acid composition within the different membrane phospholipid fractions in peripheral blood mononuclear cells in multiple sclerosis patients, and correlate with severity of neurological outcome as measured by the Kurtzke Expanded Disability Status Scale and Functional System Scores. The fatty acid composition of phosphatidylcholine, phosphatidylethanolamine, phosphatidylserine, sphingomyelin and phosphatidylinositol phospholipids in the peripheral blood mononuclear cells of twenty-six multiple sclerosis and twenty-five control subjects were measured by GC, and C-reactive protein was measured in all subjects. The elongation product of $20: 4 n-6$, $22: 4 n-6$, was significantly decreased in membrane phosphatidylethanolamine and phosphatidylserine in multiple sclerosis patients $(P=0 \cdot 01$ and $P=0.03$ respectively), and correlated inversely with severity of disease and C-reactive protein. Also an inverse correlation was observed between the C-reactive protein and membrane phosphatidylcholine and phosphatidylserine $20: 4 n-6$. Cultural and ethnic differences, as well as dietary variability, especially in a diseased state have been implicated in the differences observed in the fatty acid composition in peripheral blood mononuclear cell membranes of patients with multiple sclerosis. The present results suggest that the disease state may in part explain the reported inconsistencies in fatty acid levels in multiple sclerosis patients.
\end{abstract}

Multiple sclerosis: Fatty acids: Phospholipids: C-reactive protein: Peripheral blood mononuclear cells

The aetiology of multiple sclerosis (MS), a disease characterised by chronic inflammation of the central nervous system, is unknown, but an autoimmune and/or infectious component has been implicated ${ }^{(1-5)}$. A distinct feature of the MS brain is the appearance of lymphocytes around small blood vessels ${ }^{(4,6)}$. Fatty acids, particularly the $n-6$ fatty acids, have also been shown to have a role in the pathogenesis and treatment of the disease ${ }^{(2)}$. Phospholipids make up the basic structure of all cell membranes and the type of fatty acids present in the phospholipids are closely related to the biological features of the phospholipids ${ }^{(7,8)}$. Membrane lipids differ in their headgroup and hydrocarbon chains ${ }^{(9)}$. The polar groups can be choline, ethanolamine, serine, inositol, inositol phosphates or glycerol $^{(10)}$. The phospholipid sphingomyelin (SM), a sphingolipid, is a major component of myelin in the brain $^{(10)}$. Phosphatidylcholine (PC) is the most abundant phospholipid in animal cell membranes, and phosphatidylethanolamine $(\mathrm{PE})$ the second most ${ }^{(11,12)}$. The fatty acids contained within the different phospholipid fractions can be saturated or unsaturated (mono- or poly-), and the PUFA are subdivided into different series, the $n-9, n-6$ and $n-3$ subtypes $^{(10)}$. Membrane fatty acids fulfill a variety of roles within immune cells and changes in the membrane phospholipid composition influence immune cell function in a variety of ways ${ }^{(13)}$. These include alterations in the physical properties of the membrane, effects on cell signalling pathways, alterations in the pattern of lipid mediators produced, and an increase in eicosanoid production as part of the inflammatory process ${ }^{(13,14)}$.

Measurements of fatty acids in biological fluids and cell membranes including leucocytes from MS patients have

Abbreviations: CRP, C-reactive protein; EDSS, Expanded Disability Status Scale; FAME, fatty acid methyl esters; FSS, Functional System Score; MS, multiple sclerosis; PBMC, peripheral blood mononuclear cells; PC, phosphatidylcholine; PE, phosphatidylethanolamine; PI, phosphatidylinositol; PS, phosphatidylserine; RRMS, relapsing-remitting multiple sclerosis; SM, sphingomyelin.

* Corresponding author: Dr Tandi Matsha, fax +27 21959 6760, email matshat@cput.ac.za 
been inconsistent. Significant decreases in the relative percentages of $18: 2 n-6$ (linoleic acid), the precursor for $20: 4 n-6$, have been shown in peripheral blood lymphocyte membranes in MS patients, with accompanying lower plasma levels ${ }^{(15,16)}$, while Fisher et al. ${ }^{(17)}$ showed a similar decrease in the leucocytes of MS patients, but not in their plasma. Therefore in the present study our aim was to investigate the fatty acid composition within the different phospholipid fractions in peripheral blood mononuclear cell (PBMC) membranes of MS patients, using stringent exclusion criteria, and correlate it with severity of neurological outcome as measured by the Kurtzke Expanded Disability Status Scale (EDSS) and its Functional System Scores $(\mathrm{FSS})^{(18)}$. The exclusion criteria used in the present study included the use of fatty acid supplements, interferon and cortisone or presence of a second disease for both MS patients and control subjects. In addition we have used plasma C-reactive protein (CRP) concentrations as an inflammatory marker. CRP has been used as an inflammatory marker in assessing inflammation in MS patients ${ }^{(19,20)}$.

\section{Materials and methods}

\section{Ethical approval}

Ethical approval for the study was obtained from the Health Sciences Research Ethics Committee of the Cape Peninsula University of Technology. MS patients were contacted and recruited through the MS Society, Western Cape Branch, South Africa.

\section{Study population}

The study population consisted of twenty-six female Caucasians and twenty-five age- and sex-matched control subjects. The median age of the MS patients was 51 (range 42-62) years and that of the controls was 52 (range 40-60) years. The time since diagnosis was 9 (range 6-17) years, and the median EDSS of the MS patients was 5.25 (range 4.507.50). Five of the patients were active disease cases whilst twenty-one were in the remission phase. Of the patients in remission, eleven had had relapses 5-12 months previously, while ten patients had had no relapses during the previous year. The sample size was based on the prevalence rate given for rare diseases, which is $1 \%^{(21)}$. The patients recruited were diagnosed by a neurologist based on clinical, laboratory and MRI findings. The exclusion criteria used in the present study included the use of fatty acid supplements, interferon and cortisone or presence of a second disease for both relapsing-remitting MS (RRMS) patients and control subjects.

\section{Measurement of the disability status of patients}

The functional disability status (disease severity) of each patient was measured by a trained clinician using the Kurtzke $\operatorname{EDSS}^{(18)}$. The EDSS quantifies disability in eight functional systems and allows neurologists to assign an FSS in each of them. The functional systems are pyramidal, cerebellar, brainstem, sensory, bowel and bladder, visual, cerebral and 'other'. Higher values indicate greater disability. Scales for the total Kurtzke EDSS are from 0 to 10 , in which the 0 score indicates no disability at all and 10 indicates death due to MS.
The clinician was blinded to the results of the fatty acid analysis (i.e. the clinical evaluation was not influenced by prior knowledge of the fatty acid values).

\section{Blood sample analysis}

Venous blood $(15 \mathrm{ml})$ from both the patients and control subjects was collected into anti-coagulant EDTA tubes (Beckman Coulter South Africa (Pty) Ltd, Johannesburg, South Africa) and immediately separated using histopaque-1077 separation medium according to the manufacturer's instructions (Sigma-Aldrich (Pty) Ltd, Aston Manor, South Africa). The PBMC were washed in a $0.85 \%$ saline solution and stored in $1 \mathrm{ml}$ saline at $-80^{\circ} \mathrm{C}$. A $0.85 \%$ saline solution was used in the present study instead of the prescribed balanced PBS solution, as phosphate was inappropriate for additional tests done in the study. For all participants an extra $5 \mathrm{ml}$ EDTA blood was collected for full blood count analysis. Full blood counts were determined on a Beckman Coulter LH 750 haematology analyser: lymphocytes were $25.9 \%$ (6.89 (5.83$\left.8.48) \times 10^{9}\right)$; monocytes were $5.8 \%\left(1.52(1.05-2.00) \times 10^{9}\right)$.

The PBMC membrane fatty acid composition of PC, PE, phosphatidylserine (PS), phosphatidylinositol (PI) and SM phospholipids of RRMS patients and control subjects were measured by GC. PBMC $(800 \mu \mathrm{l})$ were extracted with chloroform-methanol $(18 \mathrm{ml} ; 2: 1, \mathrm{v} / \mathrm{v})$ according to a modified method of Folch et al. ${ }^{(22)}$. All the extraction solvents contained $0.01 \%$ butylated hydroxytoluene as an antioxidant. NEFA were separated from the total phospholipid fraction by TLC on precoated silica gel sixty plates $(10 \times 10 \mathrm{~cm})$ without a fluorescent indicator (no. 1.05721 ; Merck, Darmstadt, Germany) using the solvent system petroleum benzine (boiling point $40-60^{\circ} \mathrm{C}$ )diethyl ether (peroxide free)-acetic acid (90:30:1, by vol.) as previously described ${ }^{(23)}$. Individual phospholipid classes were separated by TLC on pre-coated silica gel 60 plates $(10 \times 10 \mathrm{~cm})$ without a fluorescent indicator (Merck) using chloroform-petroleum benzene-methanol-acetic acid-boric acid (40:30:20:10:1.8, by vol.) as solvent ${ }^{(24)}$. The lipid bands containing PC, PE, PS, PI and SM were visualised with long-wave UV light after spraying the plates with chloroform-methanol $(1: 1, \mathrm{v} / \mathrm{v})$ containing 2,5 -bis-( $5^{\prime}$-tert-butylbenzoxazolyl-[2'])thiophene $(10 \mathrm{mg} / 100 \mathrm{ml}$; Sigma-Aldrich). The lipids were transmethylated using $5 \% \mathrm{H}_{2} \mathrm{SO}_{4}$-methanol at $70^{\circ} \mathrm{C}$ for $2 \mathrm{~h}$ (SM for $18 \mathrm{~h}$ ). After cooling, the resulting fatty acid methyl esters (FAME) were extracted with $1 \mathrm{ml}$ water and $2 \mathrm{ml} n$-hexane. The top hexane layer was evaporated to dryness, redissolved in $\mathrm{CS}_{2}$ and analysed by GLC (Finnigan Focus GC, equipped with flame ionisation detection; Thermo Electron Corporation, Austin, TX, USA) using 30 m BPX 70 capillary columns of $0.32 \mathrm{~mm}$ internal diameter (SGE International Pty Ltd, Ringwood, Victoria, Australia). Gas flow rates were: $\mathrm{N}_{2}$ (make up gas), $25 \mathrm{ml} / \mathrm{min}$; air, $250 \mathrm{ml} / \mathrm{min} ; \mathrm{H}_{2}$ (carrier gas), $25 \mathrm{ml} / \mathrm{min}$, with a split ratio of $20: 1$. Temperature programming was linear at $5^{\circ} \mathrm{C} / \mathrm{min}$, initial temperature $140^{\circ} \mathrm{C}$, final temperature $220^{\circ} \mathrm{C}$, injector temperature $220^{\circ} \mathrm{C}$, and detector temperature $250^{\circ} \mathrm{C}$. The FAME were identified by comparison of the retention times with those of a standard FAME mixture (Nu-Chek Prep Inc., Elysian, MN, USA). The individual FAME were quantified against an internal standard (C17: 0; Sigma-Aldrich).

CRP concentrations were determined in a routine chemical pathology laboratory on a Beckman nephelometer 
autoanalyser using reagents from Beckman (Beckman Coulter South Africa (Pty) Ltd, Johannesburg, South Africa). The diagnostic values of this laboratory are considered positive for CRP values greater than or equal to $5 \mu \mathrm{g} / \mathrm{ml}$.

\section{Statistical analysis}

A statistics programme (STATISTICA 7; StatSoft Inc., 1984-2004, Tulsa, OK, USA) was used to perform all statistical analyses. The PBMC membrane PC, PE, PS, SM and PI phospholipid fatty acid profiles are reported in $\mu \mathrm{g}$ fatty acids/mg protein. Descriptive data are presented as median and range. For asymmetrical data the Mann-Whitney $U$ test was used to compare distributions between the cases and control subjects. Correlations between fatty acids, CRP and EDSS FSS were calculated using Spearman's rank correlation coefficient. Results were considered significant if $P$ values were less than 0.05.

\section{Results}

Differences in the fatty acid profile between relapsingremitting multiple sclerosis patients and controls

Significant differences were observed between the RRMS and control groups in their fatty acid profile. PE, PS 22:4n-6, as well as total $22: 4 n-6$, were lower in RRMS patients and control subjects

(Medians and ranges) than in the control subjects $(P=0.01, P=0.03$ and $P=0.02$ respectively) (Table 1 ).

\section{$C$-reactive protein concentrations}

No significant differences were observed in the CRP concentrations between the RRMS patients and the control subjects; however, significant inverse correlations were observed between the RRMS membrane fatty acid values and the CRP concentrations but not in the control group (Table 2). In RRMS patients with CRP values above $5 \mu \mathrm{g} / \mathrm{ml}$, PC 20:4n-6 demonstrated a decreasing trend whilst the opposite was observed in controls (Fig. 1). There was a significant positive correlation in the RRMS patients between the CRP concentrations and the EDSS ( $R$ 0.45; $P=0.03$ ) (Fig. 2).

Metabolic relationship between the fatty acids in the n-6 fatty acid series in relapsing-remitting multiple sclerosis patients and control subjects

The metabolic relationships between the $n-6$ fatty acids are summarised in Table 3. In both the RRMS and control subjects, $18: 2 n-6$ demonstrated in general a positive correlation with $20: 3 n-6,20: 4 n-6$ and $22: 4 n-6$. A positive correlation was also observed between $20: 3 n-6$ and $20: 4 n-6$, as well as between $20: 4 n-6$ and $22: 4 n-6$. However, total

Table 1. Differences in the peripheral blood mononuclear cell membrane fatty acids between relapsing-remitting multiple sclerosis (RRMS) patients

\begin{tabular}{|c|c|c|c|c|c|c|c|c|c|c|}
\hline & \multicolumn{4}{|c|}{ Fatty acids ( $\mu \mathrm{g} / \mathrm{mg}$ protein) } & \multirow[b]{3}{*}{$P$} & \multicolumn{4}{|c|}{ Percentage fatty acids } & \multirow[b]{3}{*}{$P$} \\
\hline & \multicolumn{2}{|c|}{ Controls } & \multicolumn{2}{|c|}{ RRMS patients } & & \multicolumn{2}{|c|}{ Controls } & \multicolumn{2}{|c|}{ RRMS patients } & \\
\hline & Median & Range & Median & Range & & Median & Range & Median & Range & \\
\hline PC 18:2n-6 & $4 \cdot 13$ & $3.77-4.50$ & $4 \cdot 12$ & $3.53-4.68$ & 0.84 & $9 \cdot 21$ & $8 \cdot 49-10 \cdot 12$ & 8.94 & $8 \cdot 10-9 \cdot 95$ & 0.66 \\
\hline PE $18: 2 n-6$ & 0.80 & $0.72-0.89$ & 0.75 & $0.67-0.81$ & 0.13 & 3.04 & $2 \cdot 65-3 \cdot 38$ & 3.01 & $2.72-3.43$ & 0.76 \\
\hline PS $18: 2 n-6$ & 0.11 & $0.10-0.13$ & 0.13 & $0.10-0.14$ & 0.16 & 1.25 & $1.11-1.50$ & 1.37 & $1.23-1.82$ & $0 \cdot 10$ \\
\hline PI 18:2n-6 & 0.11 & $0.09-0.12$ & 0.09 & $0.08-0.11$ & 0.25 & 1.48 & $1.23-1.98$ & 1.46 & $1.23-1.82$ & 0.92 \\
\hline SM $18: 2 n-6$ & 0.11 & $0.08-0.18$ & 0.11 & $0.07-0.16$ & 0.98 & 1.00 & $0.82-1.37$ & 0.89 & $0.65-1.60$ & 0.78 \\
\hline Total $18: 2 n-6$ & $5 \cdot 31$ & $4.96-5.72$ & $5 \cdot 30$ & $4.46-5.79$ & 0.98 & $15 \cdot 76$ & $15 \cdot 03-17.51$ & $16 \cdot 16$ & $14 \cdot 60-18 \cdot 60$ & 0.72 \\
\hline PC 20:3n-6 & 0.92 & $0.79-1.03$ & 0.89 & $0.72-1.02$ & 0.49 & 2.07 & $1 \cdot 84-2 \cdot 26$ & 2.05 & $1 \cdot 74-2 \cdot 62$ & 0.94 \\
\hline PE $20: 3 n-6$ & 0.25 & $0.22-0.29$ & 0.23 & $0.19-0.27$ & 0.19 & 0.99 & $0.91-1.12$ & 0.97 & $0.86-1.29$ & 0.59 \\
\hline PS $20: 3 n-6$ & 0.20 & $0.15-0.22$ & $0 \cdot 18$ & $0.14-0.22$ & 0.65 & $2 \cdot 12$ & $1.94-2.46$ & $2 \cdot 17$ & $1.79-2.64$ & 0.78 \\
\hline PI 20: 3n-6 & 0.09 & $0.07-0.10$ & 0.08 & $0.07-0.10$ & 0.86 & 1.17 & $1.03-1.31$ & 1.15 & $0.96-1.32$ & 0.95 \\
\hline Total $20: 3 n-6$ & 1.46 & $1.30-1.70$ & 1.40 & $1.17-1.58$ & 0.35 & $6 \cdot 27$ & $5 \cdot 88-7.04$ & 5.94 & $5 \cdot 17-7.55$ & 0.59 \\
\hline PC 20:4n-6 & 7.09 & $6 \cdot 34-8 \cdot 11$ & 7.00 & $6 \cdot 37-7 \cdot 81$ & 0.63 & $16 \cdot 11$ & $15 \cdot 03-17 \cdot 13$ & $15 \cdot 62$ & $14.73-16.93$ & 0.34 \\
\hline PE $20: 4 n-6$ & $12 \cdot 00$ & $11 \cdot 18-13 \cdot 10$ & $11 \cdot 70$ & $11 \cdot 15-12 \cdot 86$ & 0.73 & $47 \cdot 10$ & $46 \cdot 09-48 \cdot 16$ & 47.53 & $45 \cdot 63-49 \cdot 35$ & 0.56 \\
\hline PS $20: 4 n-6$ & 2.43 & $2 \cdot 11-2 \cdot 51$ & $2 \cdot 26$ & $2 \cdot 01-2 \cdot 84$ & 0.99 & $27 \cdot 52$ & $24.99-29.67$ & $26 \cdot 94$ & $24 \cdot 99-28 \cdot 38$ & 0.67 \\
\hline PI $20: 4 n-6$ & 3.34 & $3.01-3.48$ & 3.34 & $2.93-3.59$ & 0.92 & 44.83 & $43 \cdot 23-45 \cdot 57$ & $44 \cdot 21$ & $41 \cdot 20-45 \cdot 19$ & $0 \cdot 16$ \\
\hline SM $20: 4 n-6$ & 0.10 & $0.08-0.14$ & 0.10 & $0.07-0.12$ & 0.92 & 0.82 & $0 \cdot 60-1 \cdot 11$ & 0.84 & $0.60-1.33$ & 0.77 \\
\hline Total $20: 4 n-6$ & $25 \cdot 07$ & $23 \cdot 5-26 \cdot 8$ & $25 \cdot 17$ & $22 \cdot 4-26 \cdot 5$ & 0.64 & $137 \cdot 19$ & $132 \cdot 03-140 \cdot 31$ & 138.67 & $132 \cdot 33-141 \cdot 24$ & 0.57 \\
\hline PC $22: 4 n-6$ & 0.49 & $0.41-0.56$ & 0.43 & $0.37-0.55$ & $0 \cdot 19$ & $1 \cdot 10$ & $0.98-1.30$ & 1.09 & $0.93-1.27$ & 0.42 \\
\hline PE $22: 4 n-6$ & 1.72 & $1.55-1.99$ & 1.52 & $1 \cdot 15-1 \cdot 73$ & 0.01 & $6 \cdot 72$ & $5 \cdot 92-7 \cdot 25$ & $5 \cdot 81$ & $4.89-7.09$ & 0.02 \\
\hline PS $22: 4 n-6$ & 0.15 & $0.13-0.16$ & 0.13 & $0.11-0.16$ & 0.03 & 1.84 & $1.50-2.04$ & 1.63 & $1.28-1.94$ & $0 \cdot 10$ \\
\hline PI 22:4n-6 & 0.06 & $0.04-0.07$ & 0.06 & $0.04-0.07$ & 0.38 & 0.84 & $0.70-0.98$ & 0.76 & $0.63-0.90$ & 0.24 \\
\hline Total $22: 4 n-6$ & 2.47 & $2 \cdot 08-2.83$ & $2 \cdot 12$ & $1.66-2.50$ & 0.02 & $10 \cdot 91$ & $9.05-11.43$ & 9.27 & $7 \cdot 96-10 \cdot 72$ & 0.01 \\
\hline PC $22: 6 n-3$ & 0.56 & $0.52-0.67$ & 0.59 & $0.44-0.73$ & 0.79 & 1.33 & $1.11-1.60$ & 1.36 & $1.18-1.68$ & 0.79 \\
\hline PE $22: 6 n-3$ & $1 \cdot 15$ & $1.00-1.30$ & 1.09 & $0.90-1.31$ & 0.53 & 4.44 & $3 \cdot 69-5 \cdot 26$ & 4.74 & $3 \cdot 95-5 \cdot 11$ & 0.94 \\
\hline PS $22: 6 n-3$ & 0.20 & $0.16-0.22$ & $0 \cdot 17$ & $0.15-0.22$ & 0.31 & $2 \cdot 14$ & $1.95-2 \cdot 61$ & $2 \cdot 08$ & $1.77-2.49$ & 0.40 \\
\hline Total $22: 6 n-3$ & 1.91 & $1 \cdot 73-2 \cdot 25$ & 1.92 & $1 \cdot 63-2 \cdot 22$ & 0.52 & 7.91 & $7 \cdot 10-10 \cdot 28$ & $8 \cdot 51$ & $7 \cdot 28-9 \cdot 74$ & 0.99 \\
\hline
\end{tabular}

PC, phosphatidylcholine; PE, phosphatidylethanolamine; PS, phosphatidylserine; PI, phosphatidylinositol; SM, sphingomyelin. 
Table 2. Correlations between C-reactive protein values and the peripheral blood mononuclear cell membrane fatty acids in controls and relapsing-remitting multiple sclerosis (RRMS) patients

\begin{tabular}{|c|c|c|c|c|}
\hline & \multicolumn{2}{|c|}{ Controls } & \multicolumn{2}{|c|}{ RRMS patients } \\
\hline & $R$ & $P$ & $R$ & $P$ \\
\hline PC $20: 4 n-6$ & 0.01 & 0.95 & -0.45 & 0.03 \\
\hline PS $20: 4 n-6$ & 0.17 & 0.45 & -0.57 & $<0.01$ \\
\hline PS 22: 4n-6 & 0.37 & 0.07 & -0.60 & $<0.01$ \\
\hline PI $22: 4 n-6$ & 0.16 & 0.48 & -0.50 & 0.01 \\
\hline Total $18: 2 n-6$ & 0.13 & 0.57 & -0.16 & 0.48 \\
\hline Total $20: 3 n-6$ & 0.22 & 0.32 & 0.19 & 0.37 \\
\hline Total $20: 4 n-6$ & 0.09 & 0.67 & -0.33 & $0 \cdot 13$ \\
\hline Total $22: 4 n-6$ & 0.15 & 0.50 & -0.17 & 0.42 \\
\hline
\end{tabular}

PC, phosphatidylcholine; PS, phosphatidylserine; PI, phosphatidylinositol.

$18: 2 n-6$ and $20: 3 n-6$ were positively correlated in the RRMS patients only.

Correlation between the $\mathrm{n}-6$ and $\mathrm{n}-3$ fatty acids and the Kurtzke Expanded Disability Status Scale and Functional System Scores in relapsing-remitting multiple sclerosis patients

Table 4 summarises the significant correlations between PBMC membrane fatty acids and the Kurtzke EDSS and FSS. PC, PS and PI $18: 2 n-6$ showed positive correlations with the pyramidal, brainstem and bowel/bladder FSS respectively. PC and PS $20: 3 n-6$ showed positive correlations with the EDSS and cerebral FSS respectively. Total $20: 3 n-6$ also showed a positive correlation with the EDSS. Both PE and PI 20:4n-6 showed inverse correlations with the sensory FSS and PC 22:4n-6 showed an inverse correlation with the

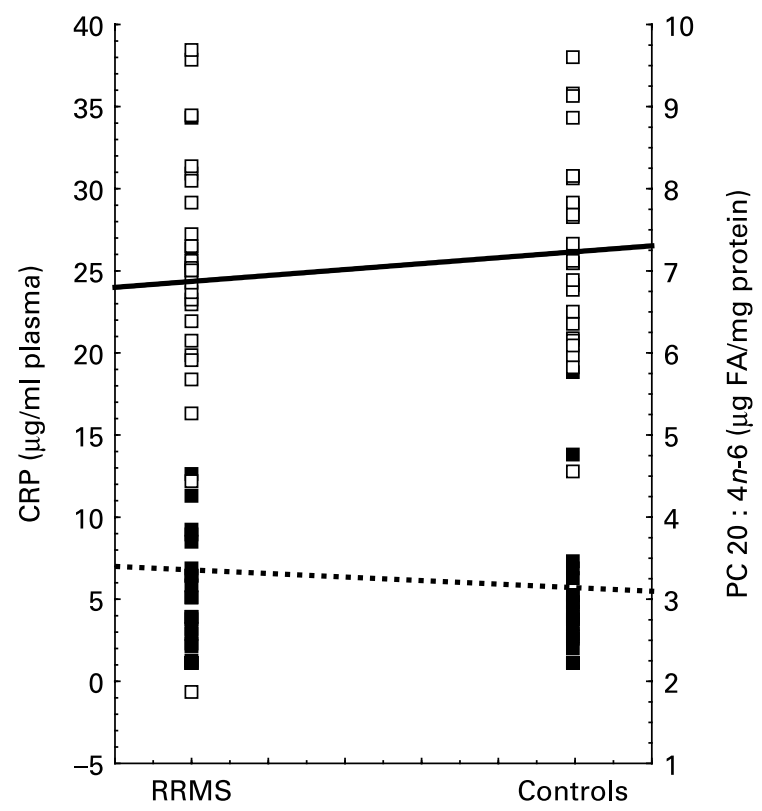

Fig. 1. C-reactive protein (CRP) (.-E.) and phosphatidylcholine (PC) 20:4n-6 ( $\square-)$ levels. In relapsing-remitting multiple sclerosis (RRMS) patients with CRP values above $5 \mu \mathrm{g} / \mathrm{ml}$, PC 20:4n-6 demonstrated a non-significant decreasing trend whilst the opposite was observed in controls. FA, fatty acids.
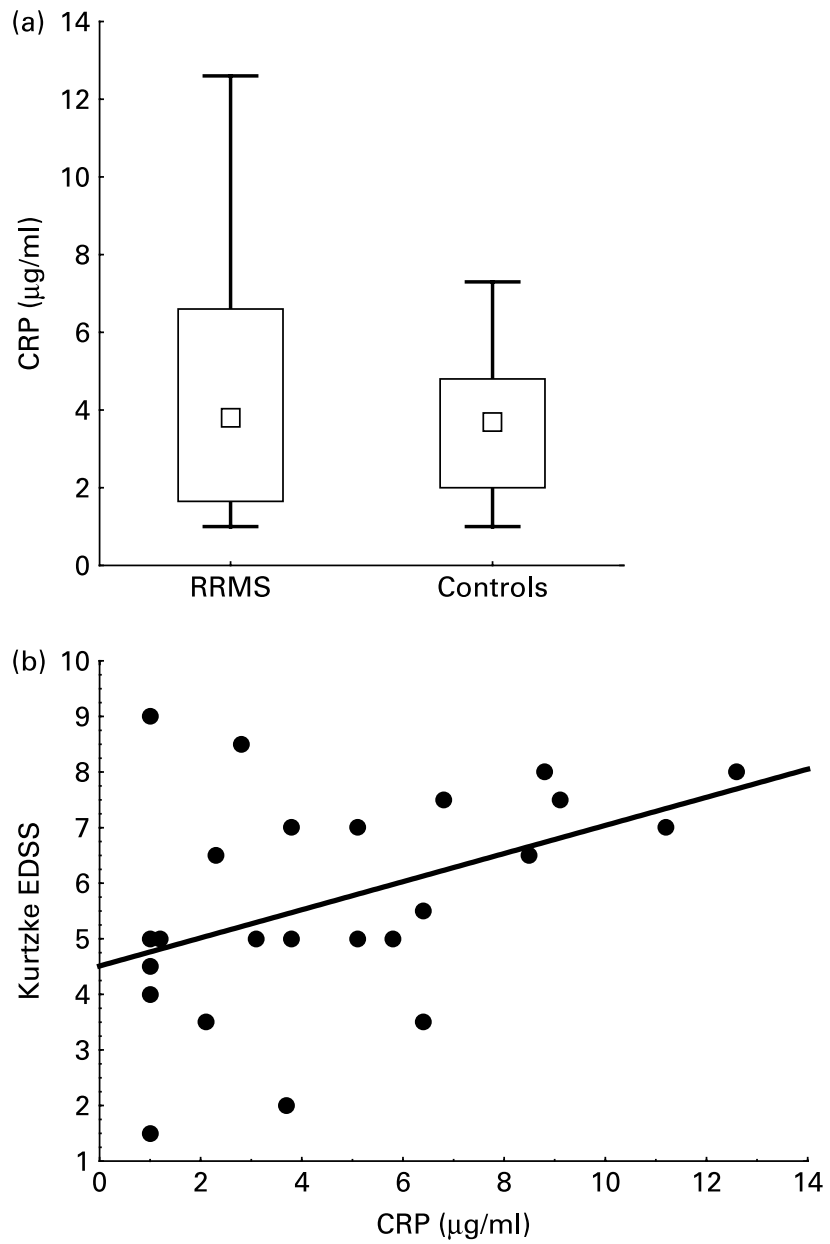

Fig. 2. C-reactive protein (CRP) levels and the Expanded Disability Status Scale (EDSS) ${ }^{(18)}$. (a) CRP levels in relapsing-remitting multiple sclerosis (RRMS) patients and control subjects. Values are medians, 25th-75th percentiles and ranges. The median for RRMS patients was 3.80 (25th-75th percentiles $1.65-6.60) \mu \mathrm{g} / \mathrm{ml}$; for controls it was 3.70 (25th-75th percentiles $2.00-4.80) \mu \mathrm{g} / \mathrm{ml}(P=0.35)$. (b) Correlation between CRP levels and the EDSS in RRMS patients. The correlation was significantly positive $(R 0.45$; $P=0.03)$.

visual FSS. Total $20: 4 n-6$ also showed an inverse correlation with the sensory FSS. In the $n-3$ fatty acid series, both PC 20:5n-3 (EPA) and PC $22: 6 n-3$ (DHA), showed positive correlations with the brainstem FSS.

\section{Discussion}

Fatty acids, particularly $18: 2 n-6$ and $20: 4 n-6$, have been shown to be reduced in the plasma, platelets, erythrocytes, leucocytes and cerebrospinal fluid of RRMS patients, but the reports are inconsistent ${ }^{(2)}$. Cultural and ethnic differences, as well as dietary variability, especially in a diseased state, have been implicated in the differences observed in these studies. In the present study, the elongation product of 20:4n-6, $22: 4 n-6$, in PBMC membrane PE and PS phospholipids was significantly decreased in the RRMS patients studied. In addition, $18: 2 n-6$ and $20: 3 n-6$ showed positive correlations with the EDSS. It is unlikely that the reduced $22: 4 n-6$ levels were due to dietary requirements as 
Table 3. Correlations between the fatty acids within the $n-6$ fatty acid series in controls and relapsing-remitting multiple sclerosis (RRMS) patients

\begin{tabular}{|c|c|c|c|c|c|}
\hline & & \multicolumn{2}{|c|}{ Controls } & \multicolumn{2}{|c|}{$\begin{array}{c}\text { RRMS } \\
\text { patients }\end{array}$} \\
\hline & & $R$ & $P$ & $R$ & $P$ \\
\hline PC $18: 2 n-6$ & PC $20: 3 n-6$ & 0.36 & 0.08 & 0.71 & $<0.01$ \\
\hline PE $18: 2 n-6$ & PE $20: 3 n-6$ & -0.05 & 0.80 & 0.57 & $<0.01$ \\
\hline PS $18: 2 n-6$ & PS $20: 3 n-6$ & 0.48 & 0.01 & 0.41 & 0.04 \\
\hline PI 18:2n-6 & PI $20: 3 n-6$ & 0.51 & 0.01 & 0.68 & $<0.01$ \\
\hline PC $18: 2 n-6$ & PC $20: 4 n-6$ & 0.45 & 0.03 & 0.54 & 0.01 \\
\hline PE $18: 2 n-6$ & PE $20: 4 n-6$ & 0.40 & 0.05 & 0.45 & 0.02 \\
\hline PS $18: 2 n-6$ & PS $20: 4 n-6$ & -0.12 & 0.57 & 0.42 & 0.03 \\
\hline SM $18: 2 n-6$ & SM $20: 4 n-6$ & 0.76 & $<0.01$ & 0.48 & 0.01 \\
\hline PI 18:2n-6 & PI $20: 4 n-6$ & 0.47 & 0.02 & 0.39 & 0.04 \\
\hline PC 20:3n-6 & PC $20: 4 n-6$ & 0.46 & 0.02 & 0.25 & $0 \cdot 21$ \\
\hline PE $20: 3 n-6$ & PE $20: 4 n-6$ & $0 \cdot 18$ & 0.40 & 0.42 & 0.03 \\
\hline PS $20: 3 n-6$ & PS $20: 4 n-6$ & 0.41 & 0.04 & 0.72 & $<0.01$ \\
\hline PI $20: 3 n-6$ & PI $20: 4 n-6$ & 0.62 & $<0.01$ & 0.60 & $<0.01$ \\
\hline PC $20: 4 n-6$ & PC $22: 4 n-6$ & 0.86 & $<0.01$ & 0.60 & $<0.01$ \\
\hline PE $20: 4 n-6$ & PE 22:4n-6 & 0.54 & 0.01 & 0.42 & 0.03 \\
\hline PS $20: 4 n-6$ & PS $22: 4 n-6$ & 0.28 & 0.18 & 0.52 & 0.01 \\
\hline PI $20: 4 n-6$ & PI $22: 4 n-6$ & 0.82 & $<0.01$ & 0.81 & $<0.01$ \\
\hline Total $18: 2 n-6$ & Total $20: 3 n-6$ & 0.32 & 0.12 & 0.65 & $<0.01$ \\
\hline Total $18: 2 n-6$ & Total $20: 4 n-6$ & 0.59 & $<0.01$ & 0.57 & $<0.01$ \\
\hline Total $20: 3 n-6$ & Total $20: 4 n-6$ & 0.52 & 0.01 & 0.41 & 0.04 \\
\hline Total $20: 4 n-6$ & Total $22: 4 n-6$ & 0.70 & $<0.01$ & 0.55 & $<0.01$ \\
\hline
\end{tabular}

PC, phosphatidylcholine; PE, phosphatidylethanolamine; PS, phosphatidylserine; PI, phosphatidylinositol; SM, sphingomyelin.

$18: 2 n-6$, the parent dietary fatty acid, was similar in both RRMS and control subjects. The $n-6$ PUFA are precursors for a number of mediators of inflammation that are released from membrane phospholipids in the course of inflammatory activation $^{(25,26)}$. It is possible that lower $n-6$ PUFA in MS could be due to an increased eicosanoid production that regulates a great number of inflammatory effects, which depends on each precursor ${ }^{(27)}$. This in turn could affect the total fatty acids pool, hence neural requirements, since the human brain requires four times the amount of $20: 4 n-6$ than $22: 6 n-3$ on a daily basis ${ }^{(2,28,29)}$. Similar to Harbige \& Sharief ${ }^{(2)}$, we have shown a disturbed relationship between $20: 3 n-6$ and $20: 4 n-6$ in the PC fraction in MS. Furthermore, we have found a reversal of the $20: 3 n-6$ and $20: 4 n-6$ relationship in the PC and PE fractions of MS PBMC membranes compared with controls. Since PE is the second most abundant phospholipid in animal cell membranes, the positive correlation between $20: 3 n-6$ and $20: 4 n-6$ in the PE fraction may be compensating for the negative correlation between $20: 3 n-6$ and $20: 4 n-6$ in the PC fraction.

CRP has been used as an inflammatory marker in assessing inflammation in RRMS patients ${ }^{(19,20)}$. Several studies have shown inverse correlation with CRP and PUFA, but inconsistencies exist in specific fatty acids ${ }^{(30-33)}$. Petersson et al. ${ }^{(33)}$ demonstrated inverse $(18: 2 n-6)$ and positive $(20: 3 n-6)$ association with CRP. Similarly, significant inverse correlations were observed between the CRP and membrane PC and PS 20:4n-6, as well as with PS and PI 22:4n-6 in RRMS cases. In contrast, in control subjects with CRP levels above $5 \mu \mathrm{g} / \mathrm{ml}$, PC 20:4n-6 demonstrated an increasing trend whilst in RRMS patients the opposite was observed. These results suggest that the degree of inflammation is an
Table 4. Correlations between membrane fatty acids and the Expanded Disability Status Scale (EDSS) and Functional System Score (FSS) in relapsing-remitting multiple sclerosis patients

\begin{tabular}{llll}
\hline Fatty acids & EDSS and FSS & $R$ & $P$ \\
\hline PC 18:2n-6 & Pyramidal & 0.42 & 0.04 \\
PS 18:2n-6 & Brainstem & 0.40 & 0.04 \\
PI 18:2n-6 & Bowel/bladder & 0.49 & 0.02 \\
PC 20:3n-6 & EDSS & 0.46 & 0.02 \\
PS 20:3n-6 & Cerebral & 0.46 & 0.02 \\
PE 20:4n-6 & Sensory & -0.45 & 0.02 \\
PI 20:4n-6 & Sensory & -0.45 & 0.02 \\
PC 22:4n-6 & Visual & -0.48 & 0.02 \\
PC 20:5n-3 & Brainstem & 0.41 & 0.04 \\
PC 22:6n-3 & Brainstem & 0.43 & 0.03 \\
Total 20:3n-6 & EDSS & 0.47 & 0.02 \\
Total 20:4n-6 & Sensory & -0.46 & 0.02 \\
\hline PC, phosphatidylcholine; & PS, phosphatidylserine; & PI, phosphatidylinositol; \\
PE, phosphatidylethanolamine. & &
\end{tabular}

important determinant of resultant fatty acid concentrations. In addition, we observed a positive correlation between CRP and disease severity as measured by the EDSS. It has been reported that serum levels of many inflammatory markers do not correlate with short-term disease progression ${ }^{(19)}$. Giovannoni et al. ${ }^{(19)}$ found no correlation between inflammatory markers, including CRP, and the EDSS, or changes in any of the MRI measured in a group of RRMS patients they studied over an 18-month period. However, in an earlier study the same authors ${ }^{(34)}$ demonstrated that raised CRP concentrations correlated with infectious episodes and clinical relapse. We think that the present results could possibly be explained by the fact that we excluded patients on disease-modifying agents, interferon and corticosteroids, which are potent anti-inflammatory agents.

The limitations of the present study were that only female patients were used and the small sample size. As we also did not consider dietary fatty acid intake, this could have affected the fatty acid levels observed in the study. The main strength of the present study is that neither the cases nor the controls were on any fatty acid supplements, and the patients were not on interferon or corticosteroid treatment. Since it is difficult to recruit patients with RRMS not on any of these medications or supplementations, this resulted in a small sample size. In conclusion, the present results concur with Harbige \& Sharief ${ }^{(2)}$ that the relationship between $n-6$ fatty acids $20: 3 n-6$ and $20: 4 n-6$ is disturbed in RRMS patients and affects the physiological integrity of immune cells. Furthermore we have shown the phospholipid fractions involved. It would, however, be of interest to investigate the role of desaturases and elongases in fatty acid metabolism in MS and other inflammatory conditions. The essential parent fatty acids, $18: 2 n-6$ and $18: 3 n-3$ ( $\alpha$-linolenic acid), cannot be synthesised in the body and must be obtained from the diet ${ }^{(35)}$. Most of the effects of $18: 2 n-6$ and $18: 3 n-3$ are dependent not only on the ingested essential fatty acids themselves, but on their derivatives $^{(36)}$. The parent dietary essential fatty acids are converted to their metabolites (the $n-6$ and $n-3$ series respectively) by a series of alternating desaturations and elongations ${ }^{(36,37)}$. The inverse correlations between fatty 
acids, CRP and disease severity and fatty acids suggest that the disease state may in part explain the reported inconsistencies in fatty acid levels in MS patients. Based on the present results, we suggest that further studies should take into account CRP levels in the interpretation of results.

\section{Acknowledgements}

We would like to extend our sincere gratitude to the following: MS Society, Western Cape Branch, South Africa and Sister Treska Botha for the recruitment of patients; Zakariya Mohammed for statistical analysis; Johanna van Wyk for technical support in the analysis of fatty acids; Dr Marius de Klerk for assisting with the measurement of the EDSS and FSS.

The present study was funded by a grant from the University Research Fund of the Cape Peninsula University of Technology.

G. H. designed the study and wrote the text. M. H. was a collaborator, was involved in the interpretation of the study and proofread the manuscript. S. J. v R. was a co-supervisor, was involved in the recruitment of volunteers for the study and proofread the manuscript. S. A. was a co-supervisor, participated in fatty acid analysis, interpretation of the study and proofread the manuscript. D. W. M. was involved in fatty acid analysis and interpretation of the study, and proofread the manuscript. P. v J. participated in fatty acid analysis and interpretation of the study, and proofread the manuscript. C. S. acted as a collaborator and proofread the manuscript. F. H. measured neurological outcome and proofread the manuscript. R. E. was a collaborator and proofread the manuscript. T. M. was the supervisor and coordinator of this group and was involved in the recruitment of volunteers for the study, and proofread the manuscript.

There are no conflicts of interest to declare.

\section{References}

1. Brück W (2005) Clinical implications of neuropathological findings in multiple sclerosis. J Neurol 252, III/10-III/14.

2. Harbige LS \& Sharief MK (2007) Polyunsaturated fatty acids in the pathogenesis and treatment of multiple sclerosis. Br J Nutr 98, Suppl. 1, S46-S53.

3. Stinissen P, Raus J \& Zhang J (1997) Autoimmune pathogenesis of multiple sclerosis: role of autoreactive $\mathrm{T}$ lymphocytes and new immunotherapeutic strategies. Crit Rev Immunol 17, 33-75.

4. Brown KA (2001) Factors modifying the migration of lymphocytes across the blood-brain barrier. Int Immunopharmacol 1, $2043-2062$.

5. Hunter SF \& Hafler DA (2000) Ubiquitous pathogens. Links between infection and autoimmunity in MS? Neurology 55, $164-165$.

6. Adams CWM (1977) Pathology of multiple sclerosis: progression of the lesion. Br Med Bull 33, 15-20.

7. Caret RL, Denniston KJ \& Topping JJ (1997) Lipids and their functions in biochemical systems. In Principles and Applications of Inorganic, Organic and Biological Chemistry, 2nd ed., pp. 379-407 [CH Wheatley, editor]. Boston: McGraw-Hill.
8. Manzoli FA, Stefoni S, Manzoli-Guidotti L, et al. (1970) The fatty acids of myelin phospholipids. FEBS Lett 10, 317-320

9. Barenholz Y \& Cevc G (2000) Structure and properties of membranes. In Physical Chemistry of Biological Surfaces, pp. 171-241 [A Baszkin and W Norde, editors]. New York: Marcel Dekker.

10. Koay ESC \& Walmsley N (1999) Plasma lipids and lipoproteins. In A Primer of Chemical Pathology, pp. 191-211. Singapore: World Scientific.

11. Williams EE (1998) Membrane lipids: What membrane physical properties are conserved during physiochemically-induced membrane restructuring? Am Zool 38, 280-290.

12. Harlos K \& Aibl H (1981) Hexagonal phases in phospholipids with saturated chains: phosphatidylethanolamines and phosphatidic acids. Biochemistry 20, 2888-2892.

13. Calder PC (2007) Immunomodulation by omega-3 fatty acids. Prostaglandins Leukot Essent Fatty Acids 77, 327-335.

14. Khanapure SP, Garvey DS, Janero DR, et al. (2007) Eicosanoids in inflammation: biosynthesis, pharmacology and therapeutic frontiers. Curr Top Med Chem 7, 311-340.

15. Tsang WM, Belin J, Monro JA, et al. (1976) Relationship between plasma and lymphocyte linoleate in multiple sclerosis. J Neurol Neurosurg Psychiatry 39, 767-771.

16. Cheravil GD (1984) Sialic acid and fatty acid concentrations in lymphocytes, red blood cells and plasma from patients with multiple sclerosis. J Neurol Sci 63, 1-10.

17. Fisher M, Johnson MH, Natale AM, et al. (1987) Linoleic acid levels in leucocytes, platelets, and serum of multiple sclerosis patients. Acta Neurol Scand 76, 241-245.

18. Kurtzke JF (1983) Rating neurologic impairment in multiple sclerosis: an expanded disability status scale (EDSS). Neurology 33, 1444-1452.

19. Giovannoni G, Miller DH, Losseff NA, et al. (2001) Serum inflammatory markers and clinical/MRI markers of disease progression in multiple sclerosis. J Neurol 248, 487-495.

20. Sellner J, Greeve I \& Mattle HP (2008) Atorvastatin decreases high-sensitivity C-reactive protein in multiple sclerosis. Mult Scler 14, 981-984.

21. Naing L, Winn $T$ \& Rusli BN (2006) Practical issues in calculating the sample size for prevalence studies. Arch Orofac Sci 1, 9-14.

22. Folch J, Lees M \& Sloane Stanley GH (1957) A simple method for the isolation and purification of total lipides from animal tissues. J Biol Chem 226, 497-509.

23. Van Jaarsveld PJ, Smuts CM, Tichelaar HY, et al. (2000) Effect of palm oil on plasma lipoprotein concentrations and plasma low-density lipoprotein composition in non-human primates. Int J Food Sci Nutr 51, S21-S30.

24. Gilfillan AM, Chu AJ, Smart DA, et al. (1983) Single plate separation of lung phospholipids including desaturated phosphatidylcholine. J Lipid Res 24, 1651-1656.

25. Bagga D, Wang L, Farias-Eisner R, et al. (2003) Differential effects of prostaglandin derived from omega-6 and omega-3 polyunsaturated fatty acids on COX-2 expression and IL-6 secretion. Proc Natl Acad Sci USA 100, $1751-1756$.

26. Simopoulos AP (2002) Omega-3 fatty acids in inflammation and autoimmune diseases. J Am Coll Nutr 21, 495-505.

27. De Pablo MA \& De Cienfuegos GA (2000) Modulatory effects of dietary lipids on immune system functions. Immunol Cell Biol 78, 31-39.

28. Horrobin DF (1999) The phospholipid concept of psychiatric disorders and its relationship to the neurodevelopmental concept of schizophrenia. In Phospholipid Spectrum Disorder in Psychiatry, pp. 3-16 [M Peet, I Glen and DF Horrobin, editors]. Carnforth, UK: Marius Press. 
29. Rappaport RS \& Dodge GR (1981) Prostaglandin E inhibits the production of human IL-2. J Exp Med 155, 943-948.

30. Yoneyama S, Miura K, Sasaki S, et al. (2007) Dietary intake of fatty acids and serum C-reactive protein in Japanese. J Epidemiol 17, 86-92.

31. Petersson H, Basu S, Cederholm T, et al. (2007) Serum fatty acid composition and indices of stearoyl-CoA desaturase activity are associated with systemic inflammation: longitudinal analyses in middle-aged men. Br J Nutr 99, 1186-1189.

32. Clarke R, Shipley M, Armitage J, et al. (2008) Plasma phospholipid fatty acids and CHD in older men: Whitehall study of London civil servants. $\mathrm{Br} J$ Nutr (epublication ahead of print version 24 December 2008).

33. Petersson H, Lind L, Hulthe J, et al. (2008) Relationship between serum fatty acid composition and multiple markers of inflammation and endothelial function in an elderly population. Atherosclerosis 203, 298-303.

34. Giovannoni G, Thorpe JW, Kidd D, et al. (1996) Soluble E-selectin in multiple sclerosis: raised concentrations in patients with primary progressive disease. J Neurol Neurosurg Psychiatry 60, 20-26.

35. Zamaria N (2004) Alteration of polyunsaturated fatty acid status and metabolism in health and disease. Reprod Nutr Dev 44, 273-282.

36. Horrobin DF \& Manku MS (1990) Clinical biochemistry of essential fatty acids. In Omega-6 Essential Fatty Acids. Pathophysiology and Roles in Clinical Medicine, pp. 21-49 [DF Horrobin, editor]. New York: Liss Inc.

37. Sprecher H (1982) Biochemistry of essential fatty acids. Prog Lipid Res 20, 13-22. 